\title{
How to Tell If a Particular Memory Is True or False
}

\author{
Daniel M. Bernstein ${ }^{1}$ and Elizabeth F. Loftus ${ }^{2}$ \\ ${ }^{1}$ Kwantlen Polytechnic University and University of Washington, and ${ }^{2}$ University of California, Irvine
}

\begin{abstract}
How can you tell if a particular memory belonging to you or someone else is true or false? Cognitive scientists use a variety of techniques to measure groups of memories, whereas police, lawyers, and other researchers use procedures to determine whether an individual can be believed or not. We discuss evidence from behavioral and neuroimaging studies and research on lying that have attempted to distinguish true from false memories.
\end{abstract}

Consider the following situation. Mary X sits on the witness stand in court, recounting an emotionally charged memory involving childhood sexual abuse. Her report is both detailed and emotional. She explains how her grandfather molested her and how she had repressed the event for many years before recovering the memory in therapy. Is Mary's report the result of a real memory or a product of suggestion or imagination or some other process?

This hypothetical example has many real-world parallels: Individuals claim that they have recovered memories of events long forgotten. Lacking corroborative evidence or a confession that can be trusted, what are we to make of these claims? Although the field of memory research has demonstrated repeatedly that memory is fallible and prone to distortion, often we are faced with a difficult question: How do we tell if a particular memory is true or false? We regard this as one of the biggest challenges in human memory research.

Cognitive scientists have developed several techniques to measure groups of memories. Also, police, lawyers, and researchers have developed techniques to help them judge whether a person can be believed or not. These two approaches-focusing on the memories reported or the person reporting the memories-represent two very different ways of answering the thorny question we have posed. Unfortunately, neither approach presently can assess whether a particular memory is true or false.

Address correspondence to Daniel M. Bernstein, Department of Psychology, Kwantlen Polytechnic University, Surrey, British Columbia V3W 2M8, Canada; e-mail: daniel.bernstein@kwantlen.ca.
We discuss these two approaches in turn, and then discuss a third approach to answering our question that involves focusing on the particular memory.

\section{FOCUSING ON GROUPS OF MEMORIES}

Historically, memory researchers have focused on groups of memories for pallid material like nonsense syllables (e.g., VIF, HOD) and words. In a typical study, subjects study a list of items (words, nonsense syllables, pictures, tones, etc.). After a delay, subjects either try to recall the studied items (recall test), or they try to recognize which items were presented prior and which items are new (recognition test). Researchers may manipulate the types of activities that subjects perform while studying and/ or remembering the items. In a word study, these activities might include a manipulation of the depth of processing in which subjects read words, generate a synonym for words (Craik \& Tulving, 1975), or even unscramble the words (Watkins \& Peynircioglu, 1990). Other manipulations include presenting semantically related word lists (e.g., dream, pillow, tired, nap, slumber) without a critical lure word that is strongly related to all the list words (e.g., sleep; Roediger \& McDermott, 1995). Subjects in these experiments then try to recall or recognize studied items. Typically, the critical lure is falsely remembered, demonstrating the fallibility of recent memory. In addition to studies involving words, researchers use groups of autobiographical memories reported by individuals to study true and false memory. In these studies, subjects recall events from their past often using diaries or other such means to record their memories.

Over the past few decades, cognitive scientists have turned to neuroscience in hopes of learning what the brain can reveal about memory and cognition. In the 1950s, Wilder Penfield, a neurosurgeon, observed a curious phenomenon when he electrically stimulated various brain regions in awake epileptic patients. Some of Penfield's patients reported fragments of thoughts and what seemed like memories. One woman reported, "I think I heard a mother calling her little boy somewhere. It seemed to be something that happened years ago ... in the neighborhood where I live" (Loftus, 1979, p. 116). Later work 
cast doubt on the fact that Penfield was uncovering actual memories.

The field of cognitive neuroscience has moved rapidly (see Poldrack \& Wagner, 2008). In this field of research, a typical memory study involves a behavioral task like those just described and a machine that permits the investigator to "peek" into the brain of the subject while the subject performs the behavioral task. These studies have revealed many insights into the brain structures and processes responsible for memory and cognition. The two most widely used neuroimaging techniques for studying human memory are event-related potentials (ERPs) and functional magnetic resonance imaging (fMRI).

ERPs have the advantage of capturing cognition in real time (good temporal resolution); however, this technique reveals little about where the cognition is occurring in the brain (poor spatial resolution). fMRI, in contrast, has good spatial resolution but poor temporal resolution. Researchers often combine these techniques to reveal temporal and spatial information within the same human subjects, using what is called an event-related fMRI procedure. Most ERP and fMRI studies of true and false memory involve semantically related word lists. Subjects study word lists and then try to recall or recognize the words from these lists. Brain activity is monitored while subjects perform this task. The results of such studies indicate valuable information about brain areas that might be associated with the production of true and false memories. In particular, sensory activity is greater for true memories than it is for false memories, regions within the medial temporal lobe seem to be involved in false memory formation, and regions within prefrontal cortex seem to be involved in memory monitoring processes resulting in the reduction of false memories (Schacter \& Slotnik, 2004).

Another procedure that provides even better temporal and spatial resolution of cognition involves surgically implanted electrodes that record electrophysiological activity in epileptic patients. Prior to surgery, these electrodes help neurosurgeons locate brain regions responsible for seizures. In one study using this procedure, subjects studied lists of words, and then tried to recall the words after a short delay. The researchers compared various brain waves in five different frequency bands (delta, theta, alpha, beta, and gamma) for words correctly and incorrectly recalled. The frequency band that best distinguished true from false memories was gamma, which the authors contend might reflect recollection of contextual information related to prior experience (Sederberg et al., 2007).

In much of the work just described, researchers measure false memories using word lists and other pallid materials like pictures and shapes. Less work has focused on autobiographical memory for entire events (see Cabeza \& St. Jacques, 2007). In the autobiographical domain, researchers ask subjects to think about personal memories while they are in a brain scanner (typically fMRI) in response to word or event cues (e.g., when is the last time you ate Chinese food?). In comparison with studies that use more pallid materials like word lists, this focus on autobiographical memories could potentially move us closer to understanding the differences between true and false memories for more interesting kinds of memories.

Although such neurophysiological techniques have advanced the field of memory research and continue to grow in popularity, experiments involving these techniques require numerous trials to yield reliable, noise-free averages. To our knowledge, nobody has developed a neurophysiological procedure that can be used to predict whether a single memory is true or false. We regard this as an important direction for future research.

\section{FOCUSING ON THE PERSON REPORTING THE MEMORIES}

As previously mentioned, memory researchers can choose to focus on groups of memories or on the individual person who is reporting the memories to try to ascertain whether a particular memory is true or false. The latter approach can be seen as an attempt to detect whether someone is lying (either intentionally or unintentionally), often using tools like the polygraph, interrogation, or other interview techniques. Such tools are used by a variety of professionals in many disciplines (e.g., police officers interview witnesses of a crime to catch the culprit; medicolegal professionals try to detect malingerers or fakers seeking financial compensation after an injury).

It is important to distinguish between two types of lying. Some people lie intentionally and for myriad reasons: financial gain, fame, popularity, even mischief. Other people lie without knowing that they are lying. In other words, they think they are telling the truth but they are reporting something that is false-a false belief or a false memory.

Catching a lie might be different depending on whether we are dealing with a deliberate lie or an unintentional false belief. First, consider the intentional liar. One can lay a trap that ensnares the intentional liar: Lies tend to beget lies, creating a web. Often, one slip is all that is required to catch the liar in a web of lies. Also, we may look to the past for clues that one is lying now. After all, past behavior is often said to be the best predictor of future behavior. Some liars lie repeatedly. If we know that someone tends to lie, we might be inclined to think that s/he is lying now. But some liars may not lie often. If the person has no real history of lying, then we are not likely to think that s/he is lying now. So, past behavior can be informative, but it is a blunt instrument indeed for determining whether one is lying or telling the truth now. Other methods for detecting deception have been explored. One potentially fruitful avenue involves microexpressions of facial emotions (Ekman, 1992), especially inconsistent facial expressions exhibited by deceivers (Porter \& Brinke, 2008).

But how do you catch a liar who is unaware that s/he is lying? If someone believes earnestly that he ate a large spider as a child, but in actuality he did not, how can we spot this falsehood? The simple, yet unsatisfying, answer is that we cannot determine 
this with certainty. We can examine the content of his memory report for clues that this event occurred (more on this later). We can also look at individual difference measures used by psychologists to determine who is most likely going to harbor a falsehood. Among these measures are the Gudjonsson Suggestibility Scale, the Creative Imagination Scale, the MarloweCrowne Social Desirability Scale, the Dissociative Experiences Scale, and working memory, to name just a few. Although all of these measures have been shown to correlate with false memory (see Hyman \& Billings, 1998), the findings are mixed. Some have reported null effects and failures to replicate previous work using these same measures (Laney, Bowman Fowler, Nelson, Bernstein, \& Loftus, 2008). At least one reason for the mixed findings is that both individual differences and false memories are measured differently across studies. What is needed is a meta-analysis of individual differences in false memory formation. What is also needed is a battery of self-report and behavioral measures to try to predict who will be susceptible to forming false beliefs and memories.

\section{FOCUSING ON A PARTICULAR MEMORY}

To recap, researchers can focus on groups of memories or on the individual reporting the memory to determine whether a particular memory is true or false. One approach to determining if an individual memory report is authentic is to analyze the contents of the memory report. Investigators have developed several procedures for assessing the validity of written and verbal statements concerning events. In the laboratory, we have the advantage of knowing who is reporting accurately and who is reporting falsely as we have control over the materials and methods. We can control which events the person experiences and which events are new. The challenge, though, is to apply what we have learned from the laboratory to the real world, where experiences can be highly emotional and even traumatic. Also, in the real world, we do not know who is telling the truth and who is lying or which memories are true and which are false.

After a suggestion-free memory report has been obtained from someone, how do we determine if it is true or false? One popular technique used by researchers is criteria-based content analysis. Originally developed for children, this technique also applies to adults. The idea behind criteria-based content analysis is that false statements are inherently different from and differentiable from true statements. This assumption applies both to lies and false beliefs and memories. The technique involves the scoring of memory reports using 19 cognitive and motivational criteria that are present or absent in the report (e.g., logical structure, unusual details, spontaneous corrections). These criteria have had some success in differentiating true from false memory reports; however, the differences are relatively small when controlled-laboratory experiments are examined. In a review of 37 studies, amount of detail was the criterion that best differentiated true from false statements (see Vrij, 2005).
Consistent with other work, true memory reports tend to contain more detail-especially sensory detail like sight, sound, touch, taste, and smell-than do false memories (Schooler, Gerhard, \& Loftus, 1986; Suengas \& Johnson, 1988). Criteria-based content analysis appears to be most useful as a first step in helping police investigators form rough ideas about the truthfulness of witness statements (Vrij, 2005).

Many cases of allegedly recovered memories have turned out to be false memories implanted by well-meaning therapists who use suggestion and imagination to guide the search for memories. The more elaborate and detailed the implanted false memory is, the more real and authentic it will seem to the individual, and the harder it will be to determine whether it is true or false. What techniques can be used to determine whether the unintentional liar holds a false belief?

Recently, we have moved from planting event details in people's minds to planting entirely false memories. Our methods involve strong suggestion and imagination of event details, combined with painstaking efforts to ensure that the memory that we are suggesting is, in fact, a false memory for the individual. For example, Loftus and Pickrell (1995) asked parents of subjects to describe three actual events that occurred in their child's life. Subjects then read these three events, in addition to a false event ("You got lost in the mall for an extended period of time before being reunited with your parent." Note that parents verified that this event had not occurred in their child's life). Subjects were told that their parent(s) had supplied the events. Subjects tried to recall each of these four events. Over three successive interviews, separated by 1 week each, $25 \%$ of subjects came to believe that they had been lost in the mall as a child.

In subsequent research, other false memories have been planted, including being hospitalized overnight for an ear infection, spilling a punch bowl on the bride's parents at a wedding, getting one's hand caught in a mousetrap, hiding the toy slime in the teacher's desk, and even witnessing a demonic possession (see Lindsay, Hagen, Read, Wade, \& Garry, 2004, for review). In these studies, experimenters try to ensure that the false event in question did not actually occur in the subject's life. Typically, this is achieved by verifying with the parents that the false event did not occur. Sometimes researchers select key events to plant that could not have occurred. For example, subjects in one study were told falsely that they had received a skin graft as part of a routine medical procedure as a child. The researchers chose this event because it was not a routine medical procedure performed on children in the country where the research was conducted (Mazzoni \& Memon, 2003).

In another study, subjects who viewed a suggestive advertisement for Disney came to believe that, as children, they had met and shook hands with Bugs Bunny at Disneyland. For anyone who knows anything about Disney, you will realize that such an event is impossible. Bugs Bunny is a Warner Brothers character, and Disney does not have Warner Brothers' charac- 
ters in its theme parks (Braun, Ellis, \& Loftus, 2002). Even with impossible events, a substantial minority of subjects come to believe that the false event occurred in their past. This work tells us much about the formation of what we call rich false memories-detailed memories for individual events that never occurred. However, like the focus on groups of memories and on the individual reporting the memory, the focus on single rich memories presently does not tell us whether a particular memory is true or false.

\section{FUTURE DIRECTIONS FOR MEMORY RESEARCH}

So, where might memory researchers profitably focus their attention in the future? We have posed one question here that we think deserves special attention. However, as we have noted, it might be virtually impossible to tell reliably if a particular memory is true or false without independent corroboration. A focus on groups of memories and on the individual reporting the memory provides useful information about the mechanisms underlying true and false memory. Unfortunately, such approaches cannot answer our question. Also, past work involving word lists and other pallid materials is far removed from the richer autobiographical memories that the courts care about. A potentially profitable direction for the future might be to focus on rich false memories. The field has begun to compare true memories with rich false memories, and so far few differences have emerged. Continuing this line of work may reveal more robust differences and move us closer to our goal of being able to tell if a particular memory is true or false.

We believe that the best approach to helping us determine the veracity of a particular memory is to cull our knowledge from all three approaches discussed in this paper: the focus on groups of memories, the individual reporting the memory, and the single rich memory. When we obtain better imaging tools and analysis techniques, better individual difference measures (perhaps a battery of such measures used in conjunction with a battery of behavioral measures), and tools not yet invented, we might combine these measures in some way to predict whether a particular memory is likely true or false. Formal mathematical models and statistical procedures (like discriminant function analysis and structural equation modeling) might also be developed and combined with neuroimaging and behavioral techniques to help researchers determine the veracity of a particular memory.

At present, more work needs to be done to determine what tasks, measures, and techniques are required to distinguish a true from a false memory. Once these methods are obtained, they might be combined to predict the veracity of a given memory.

\section{CONCLUSION}

Let's return to Mary $\mathrm{X}$ in the courtroom. She has finished recounting the details of her childhood abuse. Without indepen- dent corroboration from another person or hard evidence that the abuse occurred (e.g., a recently discovered medical report verifying and detailing the abuse), how can we determine whether Mary's memory is real? On average, real memories have more sensory and conceptual information, including visual, auditory, and olfactory details and spatial and temporal details (Suengas \& Johnson, 1988). So, we might closely examine Mary’s memory report to see if it has sensory detail. But even if we find such detail, how can we be sure that the memory is real and not the product of suggestion? We now know that suggestion and imagination can make a false memory feel and appear real.

In essence, all memory is false to some degree. Memory is inherently a reconstructive process, whereby we piece together the past to form a coherent narrative that becomes our autobiography. In the process of reconstructing the past, we color and shape our life's experiences based on what we know about the world. Our job as memory researchers and as human beings is to determine the portion of memory that reflects reality and the portion that reflects inference and bias. This is no simple feat, but one worthy of our continued investigation.

\section{REFERENCES}

Braun, K.A., Ellis, R., \& Loftus, E.F. (2002). Make my memory: How advertising can change our memories of the past. Psychology and Marketing, 19, 1-23.

Cabeza, R., \& St. Jacques, P.L. (2007). Functional neuroimaging of autobiographical memory. Trends in Cognitive Sciences, 11, 219227.

Craik, F.I.M., \& Tulving, E. (1975). Depth of processing and the retention of words in episodic memory. Journal of Experimental Psychology: General, 104, 268-294.

Ekman, P. (1992). Telling lies: Clues to deceit in the marketplace, politics, and marriage. New York: Norton.

Hyman, I.E., \& Billings, F.J. (1998). Individual differences and the creation of false childhood memories. Memory, 6, 1-20.

Laney, C., Bowman Fowler, N., Nelson, K.J., Bernstein, D.M., \& Loftus, E.F. (2008). The persistence of false beliefs. Acta Psychologica, 129, 190-197.

Lindsay, D.S., Hagen, L., Read, J.D., Wade, K.A., \& Garry, M. (2004). True photographs and false memories. Psychological Science, 15, 149-154.

Loftus, E.F. (1979). Eyewitness testimony. Cambridge, MA: Harvard University Press.

Loftus, E.F., \& Pickrell, J.E. (1995). The formation of false memories. Psychiatric Annals, 25, 720-725.

Mazzoni, G.A.L., \& Memon, A. (2003). Imagination can create false autobiographical memories. Psychological Science, 14, 186-188.

Poldrack, R.A., \& Wagner, A.D. (2008). Introduction to the special issue: The interface between neuroscience and psychological science. Current Directions in Psychological Science, 17, 61.

Porter, S., \& Brinke, L.T. (2008). Reading between the lies: Identifying concealed and falsified emotions in universal facial expressions. Psychological Science, 19, 508-514.

Roediger, H.L. III., \& McDermott, K.B. (1995). False perceptions about false memories. Journal of Experimental Psychology: Learning, Memory, and Cognition, 22, 803-814. 
Schacter, D.L., \& Slotnik, S.D. (2004). The cognitive neuroscience of memory distortion. Neuron, 44, 149-160.

Schooler, J.W., Gerhard, D., \& Loftus, E.F. (1986). Qualities of the unreal. Journal of Experimental Psychology: Learning, Memory, and Cognition, 12, 171-181.

Sederberg, P.B., Schulze-Bonhage, A., Madsen, J.R., Bromfield, E.B., Litt, B., Brandt, A., \& Kahana, M.J. (2007). Gamma oscillations distinguish true from false memories. Psychological Science, 18, 927-932.
Suengas, A.G., \& Johnson, M.K. (1988). Qualitative effects of rehearsal on memories for perceived and imagined complex events. Journal of Experimental Psychology: General, 117, 377-389.

Vrij, A. (2005). Criteria-based content analysis: A qualitative review of the first 37 studies. Psychology, Public Policy, and Law, 11, 3-41.

Watkins, M.J., \& Peynircioglu, Z.F. (1990). The revelation effect: When disguising test items induces recognition. Journal of Experimental Psychology: Learning, Memory, and Cognition, 16, 1012-1020. 